\title{
Treatment of Acute Left-Sided Heart Failure with Intramuscular Injection of Chlorpromazine
}

\author{
Junichiro Mrfune, M.D., Kizuku Kuramoto, M.D., Keiji Ufda, M.D., \\ Satoru Matsushita, M.D., Iwao Kuwajima, M.D., Makoto Sakal, M.D., \\ Tsutomu Iwasaki, M.D., Hiroshi Inoue, M.D., Tatsuo \\ Shinagawa, M.D., and Mototaka Murakami, M.D.
}

\section{SUMMARY}

Hemodynamic responses to intramuscular injection of 5 to $10 \mathrm{mg}$ (average $8.5 \mathrm{mg}$ ) of chlorpromazine were assessed in 10 patients with acute left-sided heart failure (treated group). Left ventricular filling pressure, blood pressure, heart rate, and cardiac index were measured before the injection and for 6 hours thereafter. In 8 patients with heart failure, the same hemodynamic monitoring was performed without the injection of chlorpromazine (control group).

In treated group significant reduction of left ventricular filling pressure was observed at $5 \mathrm{~min}$ after the injection of chlorpromazine. Left ventricular filling pressure showed a peak reduction from an average of 27.2 to $18.8 \mathrm{mmHg}(-30.8 \%, \mathrm{p}<0.001)$ at $15 \mathrm{~min}$, and a significant reduction persisted for 6 hours. At $15 \mathrm{~min}$, mean blood pressure was reduced slightly (101 to $92 \mathrm{mmHg},-9.0 \%, \mathrm{p}<0.05)$ and cardiac index tended to increase slightly $\left(2.11\right.$ to $2.28 \mathrm{~L} / \mathrm{min} / \mathrm{M}^{2},+7.8 \%$, NS $)$. Heart rate was unchanged. Relief of symptoms of pulmonary congestion was also observed within $15 \mathrm{~min}$. Improvement of symptoms of pulmonary congestion was more prominent particularly in 3 patients who had severe dyspnea and stridor. In control group, left ventricular filling pressure, blood pressure, and heart rate showed no significant change over 6 hours.

The present study suggested that intramuscular injection of chlorpromazine at the dosage of 5 to $10 \mathrm{mg}$ showed rapid and marked clinical improvement without significant side effects and therefore its use may be indicated in patients with acute left-sided heart failure, especially in paroxysmal episodes.

\section{Additional Indexing Words :}

Vasodilator Hemodynamic effect Left ventricular filling pressure Blood pressure Cardiac index Sedative effect

From the Department of Internal Medicine, Tokyo Metropolitan Geriatric Hospital, Tokyo, Japan.

Address for reprint: Junichiro Mifune, M.D., Department of Internal Medicine, Tokyo Metropolitan Geriatric Hospital, Sakae-cho 35, Itabashi-ku, Tokyo 173, Japan.

Received for publication June 20, 1978. 
$\mathrm{A}^{\mathrm{c}}$

CUTE left-sided heart failure is a frequent cause of death in patients with ischemic heart disease, hypertension, aortic valvular disease, or mitral regurgitation. A number of works have demonstrated the effectiveness of vasodilators such as phentolamine, sodium nitroprusside and nitroglycerin in the treatment of heart failure. ${ }^{1-4)}$ But these agents have not sedative effect which helps to eliminate restlessness, hyperventilation, or sensation of dyspnea of patients. It is well known that morphine is one of the most useful drugs in the treatment of paroxysmal episodes associated with heart failure. ${ }^{5)}$ The clinical benefits are often striking and appear rapidly by its vasodilating and sedative effects. However, its wide use as a common therapeutic agent is restricted in Japan because of the regulations for narcotics.

Chlorpromazine, one of the major tranquilizers, has a potent vasodilating effect in addition to sedative effect. ${ }^{6}$ ) That beneficial vasodilating effect of chlorpromazine has been applied for cardiovascular disorders mainly to improve tissue perfusion in patients with cardiogenic shock following open heart surgery, acute myocardial infarction or pulmonary embolism. ${ }^{71-91}$

In this study, we have demonstrated the rapid and potent hemodynamic effects of chlorpromazine injected intramuscularly in patients with acute leftsided heart failure.

\section{Subjects And Methods}

Ten patients, 1 man and 9 women, aged 67 to 87 (average 74.8 ) years, who were treated with chlorpromazine, constituted the treated group. They had clinical evidence of acute left-sided heart failure when admitted to the Coronary Care Unit. Five patients had acute myocardial infaction, 3 had chronic ischemic heart disease, and 2 had hypertensive heart disease. Chlorpromazine was injected intramusculary in a single dose of 5 to $10 \mathrm{mg}$, averaging $8.5 \mathrm{mg}$.

Eight patients, 2 men and 6 women, aged 68 to 81 (average 74.7) years, who did not receive the injection of chlorpromazine on the day of investigation, constituted control group. The symptoms of heart failure in this group were stable and not so severe as treated group. Three patients had acute myocardial infarction, 4 had chronic ischemic heart disease, and 1 had hypertensive heart disease.

Right heart catheterization was performed in the Coronary Care Unit using a Swan-Ganz triple lumen catheter inserted from the saphenous vein. Pulmonary arterial and pulmonary capillary wedge pressure were obtained using a strain gauge transducer (Nihonkohden MPU 0.5). Electrocardiographic and pressure recording were made on a direct pen-recorders (Nihonkohden RM 45). Cardiac output (CO) were measured by thermodilution technique using Columbus 108 thermodilution cardiac output computer. ${ }^{4,10)}$ Blood pressure (BP) was obtained with a sphygmomanometer. Pulmonary capillary wedge pressure or pulmonary arterial diastolic pressure was designated as left ventricular filling pressure (LVEP). The following calculation were made. 
Mean Blood Pressure (MBP)

$$
=\text { Diastolic BP }+\frac{(\text { Systolic BP-Diastolic BP })}{3}(\mathrm{mmHg})
$$

Total Peripheral Resistance Index (TPRI)

$$
=\frac{\mathrm{MBP} \times 80}{\text { Cardiac Index }}\left(\mathrm{dyne} \cdot \mathrm{sec} \cdot \mathrm{cm}^{-5} \cdot \mathrm{M}^{2}\right)
$$

Stroke Work Index $(\mathrm{SWI})=$ Stroke Index $\times(\mathrm{MBP}-\mathrm{LVFP}) \times 0.0136\left(\mathrm{Gm} / \mathrm{M}^{2}\right)$

Hemodynamic measurements were made before a single injection of chlorpromazine and after 5, 10, 15, 30 min and 1, 2, 3, 4, 5, 6 hours in the treated group. In the control group, hemodynamic measurements were also performed in the same fashion without chlorpromazine.

\section{Results}

Percent changes in left ventricular filling pressure and mean blood pressure both in treated group and control group were shown in Figs. 1 and 2. In treated group, a significant reduction of left ventricular filling pressure was observed at $5 \mathrm{~min}$ after the injection of chlorpromazine (mean $-16.6 \%$,

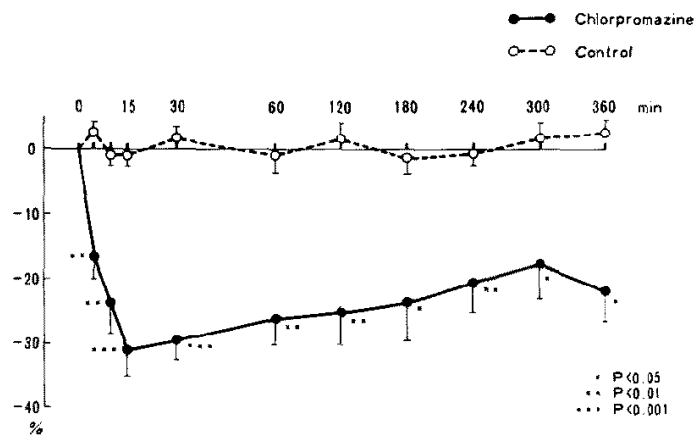

Fig. 1. Time course of changes in left ventricular flling pressure in 10 patients who were treated with chlorpromazine (Chlorpromazine) and 8 patients without treatment (Control).

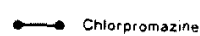

- $-\infty$ Control

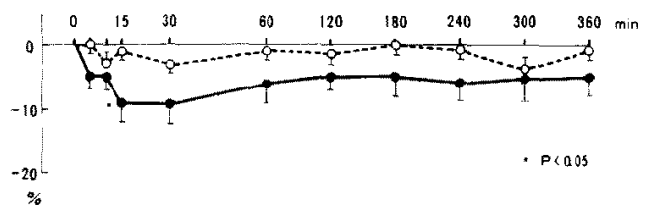

Fig. 2. Time course of changes in mean blood pressure in 10 patients who were treated with chlorpromazine (Chlorpromazine) and 8 patients without treatment (Control). 
$\mathrm{p}<0.01)$. Left ventricular filling pressure showed a peak reduction at $15 \mathrm{~min}$ (mean $-30.8 \%, \mathrm{p}<0.001$ ) and a significant reduction persisted for 6 hours. Mean blood pressure in treated group showed the time course which was similar to that of left ventricular filling pressure. But the changes were less pronounced and only at 15 min mean blood pressure showed a significant reduction (mean $-9.0 \%, \mathrm{p}<0.05$ ). In control group, left ventricular filling pressure and mean blood pressure showed no significant change over 6 hours.

Hemodynamic data before and $15 \mathrm{~min}$ after the injection of chlorpromazine were presented in Table $I$ and Figs. 3, 5, 6 and percent changes following the injection were shown in Fig. 4. The left ventricular filling pressure was reduced in all patients from an average of $27.2 \pm 1.4$ (mean $\pm \mathrm{SE}$ ) to $18.8 \pm 1.6 \mathrm{mmHg}(\mathrm{p}<0.01)$, with percent reduction ranging from 6 to $46 \%$ (mean $-30.8 \%, \mathrm{p}<0.001$ ). In 3 patients who showed severe dyspnea and stridor, the reduction (mean $-37 \%$ ) was greater than in the remaining 7 patients without stridor (mean $-28 \%$ ). Mean blood pressure decreased in 8 patients and rose in 2 patients. The average mean blood pressure was reduced slightly from $101 \pm 6$ to $92 \pm 6 \mathrm{mmHg}$ (mean $-9.0 \%, \mathrm{p}<0.05$ ). Heart rate showed no significant change.

Cardiac index increased in 7 patients, unchanged in 2 patients and decreased in 1. The average cardiac index increased slightly, although not

Table I. Hemodynamic Findings Before and 15 Min (Peak Effect) after Injection of Chlorpromazine

\begin{tabular}{|c|c|c|c|c|c|c|c|c|c|c|c|}
\hline \multirow[b]{2}{*}{ Patient no. } & \multicolumn{2}{|c|}{$\begin{array}{c}\mathrm{LVFP} \\
(\mathrm{mmHg})\end{array}$} & \multicolumn{2}{|c|}{$\frac{\mathrm{MBP}}{(\mathrm{mmHg})}$} & \multicolumn{2}{|c|}{$\frac{\text { HR }}{\text { (beats/min) }}$} & \multicolumn{2}{|c|}{$\underset{\left(L / \min / M^{2}\right)}{\text { CI }}$} & $\begin{array}{c}\text { TPRI } \\
\left(\text { dyne }-\sec ^{-}\right. \\
\left.\mathrm{cm}^{-5} \cdot \mathbf{M}^{2}\right)\end{array}$ & \multicolumn{2}{|c|}{$\begin{array}{c}\text { SWI } \\
\left(\mathrm{Gm} / \mathrm{M}^{2}\right)\end{array}$} \\
\hline & before & after & before & after & before & after & betore & after & before after & before & after \\
\hline 1 & 23 & 18 & 78 & 65 & 79 & 78 & 3.15 & 3.62 & $1,396 \quad 1,038$ & 29.7 & 29.6 \\
\hline 2 & 25 & 16 & 90 & 85 & 89 & 83 & 2.11 & 2.30 & $2,464 \quad 2,400$ & 21.0 & 26.0 \\
\hline 3 & 23 & 14 & 90 & 78 & 60 & 54 & 2.12 & 2.22 & $2,5282,306$ & 32.2 & 35.8 \\
\hline 4 & 32 & 30 & 98 & 101 & 74 & 68 & 1.68 & 1.83 & $3,1423,103$ & 20.4 & 26.0 \\
\hline 5 & 22 & 16 & 81 & 84 & 63 & 68 & 1.85 & 2.23 & $2,5512,439$ & 23.5 & 30.2 \\
\hline 6 & 34 & 20 & 148 & 128 & 98 & 97 & 2.43 & 2.46 & $2,5672,341$ & 26.2 & 24.8 \\
\hline 7 & 32 & 25 & 98 & 96 & 96 & 97 & 2.03 & 1.81 & $2,6002,696$ & 18.9 & 15.4 \\
\hline 8 & 23 & 18 & 116 & 114 & 108 & 108 & 1.44 & 1.49 & $5,1665,154$ & 16.8 & 17.9 \\
\hline 9 & 32 & 17 & 104 & 92 & 90 & 84 & 2.14 & 2.74 & $2,6912,189$ & 23.2 & 33.2 \\
\hline 10 & 26 & 14 & 104 & 82 & 102 & 101 & 2.19 & 2.16 & $2,8492,518$ & 22.7 & 19.7 \\
\hline Mean & 27.2 & 18.8 & 101 & 92 & 85.9 & 83.8 & 2.11 & 2.28 & $2,7952,618$ & 23.5 & 25.9 \\
\hline $\mathrm{SE}$ & 1.4 & 1.6 & 6 & 6 & 5.1 & 5.4 & 0.14 & 0.18 & $298 \quad 326$ & 1.5 & 2.1 \\
\hline $\mathrm{p}$ & $<0$ & .01 & $\mathrm{~N}$ & & $\mathrm{~N}$ & & N & & NS & NS & \\
\hline
\end{tabular}

$\mathbf{L V F P}=$ left ventricular filling pressure; $\mathrm{MBP}=$ mean blood pressure; $\mathrm{IR}=$ heart rate; $\mathrm{CI}=$ cardiac index; TPRI =total peripheral resistance index; SWI =stroke work index. 
significant, from $2.11 \pm 0.14$ to $2.28 \pm 0.18 \mathrm{~L} / \mathrm{min} / \mathrm{M}^{2}$ (mean $+7.8 \%$, NS). Thecardiac index was plotted against left ventricular filling pressure and left ventricular function curves were constructed for each of 10 patients (Fig. 5). In all but 1 case, the curves were shifted to the left or to upper left. Stroke work index increased in 6 patients, unchanged in 1 and decreased in 2 . The average stroke work index tended to increase slightly from $23.5 \pm 1.5$ to $25.9 \pm 2.1 \mathrm{Gm} / \mathrm{M}^{2}$ (mean $+10.4 \%$, NS). Total peripheral resistance index

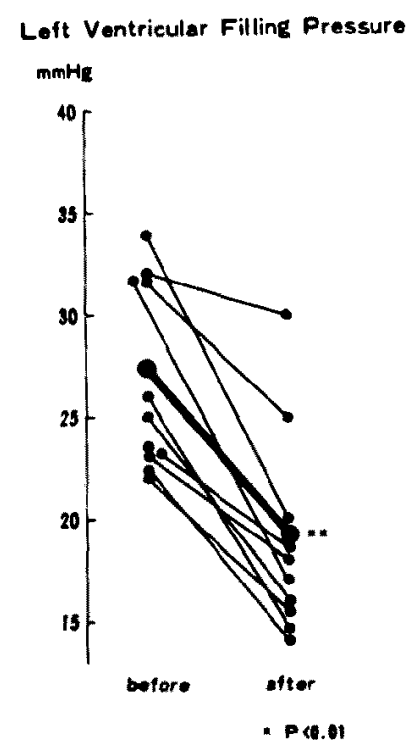

Hert Rete

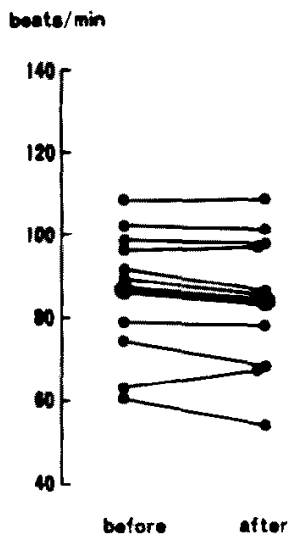

Mean Blood Pressure

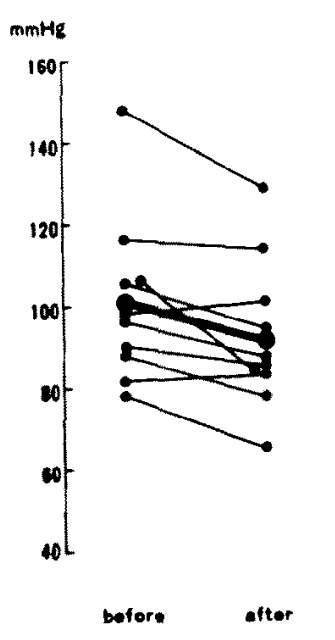

Cerdiec Index

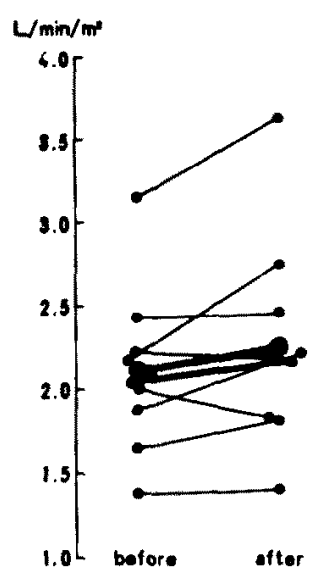

Fig. 3. Changes in left ventricular filling pressure (LVFP), mean blood pressure (MBP), cardiac index (CI) and heart rate (HR) observed $15 \mathrm{~min}$ after injection of chlorpromazine. The thick lines indicate the mean changes. 


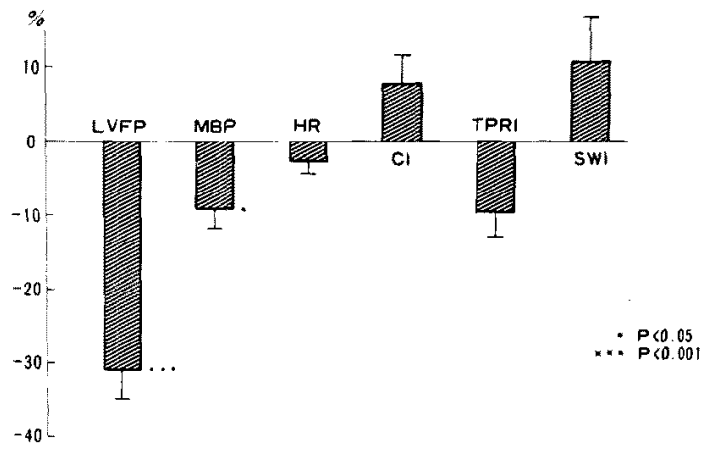

Fig. 4. Percent changes observed $15 \mathrm{~min}$ after injection of chlorpromazine. $L V F P=$ left ventricular filling pressure; $M B P=$ mean blood pressure; $H R=$ heart rate; $C I=$ cardiac index; $T P R I=$ total peripheral resistance index; SWI $=$ stroke work index.

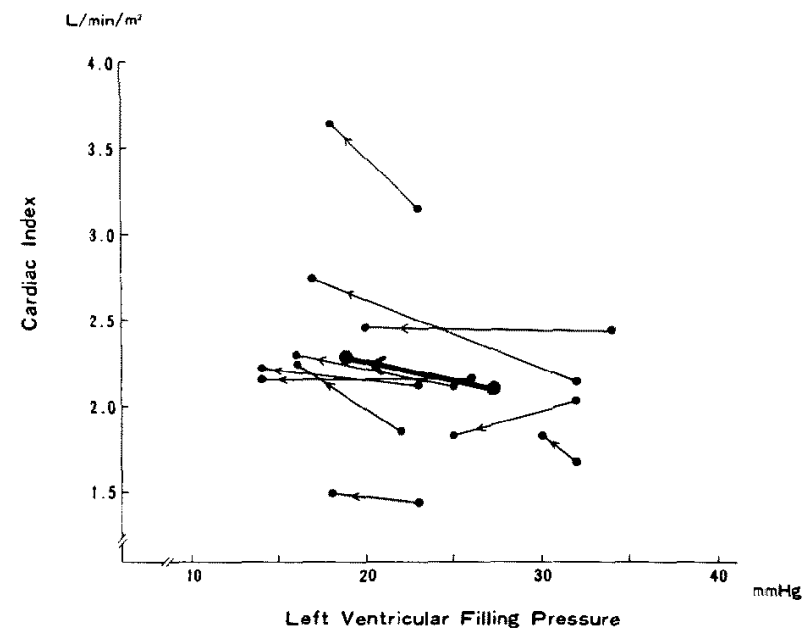

Fig. 5. Changes in left ventricular filling pressure and cardiac index observed $15 \mathrm{~min}$ after injection of chlorpromazine. Arrows represent the direction of changes after injection of chlorpromazine. The thick arrow indicates the mean change.

tended to reduce slightly from an average of $2,795 \pm 298$ to $2,618 \pm 326$ dyne. $\mathrm{sec} \cdot \mathrm{cm}^{-5} \cdot \mathrm{M}^{2}$ (mean $-9.5 \%, \mathrm{NS}$ ).

Clinical symptoms of pulmonary congestion disappeared or decreased in all patients within $15 \mathrm{~min}$ after the injection of chlorpromazine. Particularly, in 3 patients who had severe dyspnea and stridor, the improvement of symptoms was more prominent and rapid. Significant side effects were not observed in any patients. Ventricular premature contractions disappeared in 1 of 5 patients after the injection of chlorpromazine, but frequency of arrhythmia was not increased in any other patients. 


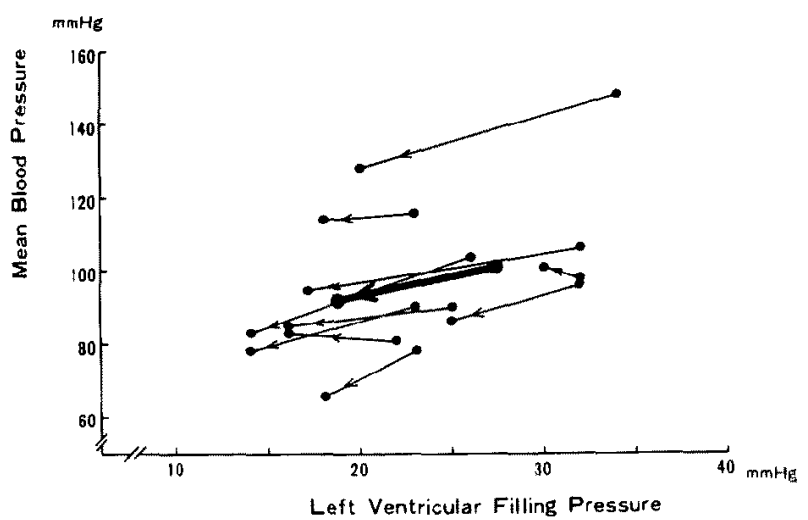

Fig. 6. Changes in left ventricular fllling pressure and mean blood pressure observed $15 \mathrm{~min}$ after injection of chlorpromazine. Arrows represent the direction of changes after injection of chlorpromazine. The thick arrow indicates the mean change.

\section{Discussion}

In patients with heart failure, preload reduction by dilatation of the venous system decreases left ventricular filling pressure and pulmonary congestion. Afterload reduction by dilation of arterial system results in an improvement in ejection fraction, a reduction in cardiac work and oxygen demand. ${ }^{2,11)}$ Chlorpromazine has a potent vasodilating effect due to both its effect on the autonomic nervous system and direct action on blood vessels. ${ }^{61}$ In this study, the hemodynamic response to intramuscular injection of chlorpromazine in patients with acute left-sided heart failure showed that elevated left ventricular filling pressure was reduced from an average of 27.2 to $18.8 \mathrm{mmHg}$ (mean $-30.8 \%$ ) at the time of maximal effect. Mean blood pressure was also reduced from an average of 101 to $92 \mathrm{mmHg}$ (mean $-9.0 \%$ ), but percent change was smaller than that in left ventricular filling pressure. From these observations, chlorpromazine appears to show a greater preload reduction than afterload reduction.

Recently, Elkayam and Rotmensh reported the effect of chlorpromazine administered intravenously to patients with acute myocardial infarction and pump failure. ${ }^{12)}$ Their observations are in close agreement with our findings, although the way of administration is different. In their report, pulmonary arterial wedge pressure was reduced, as an average, by $38.2 \%$ and mean arterial pressure was reduced by $18.3 \%$.

It has been considered that the vasodilator effect of chlorpromazine is, in part, related to its peripheral alpha-blocking action. ${ }^{6), 7)}$ However, our study suggests that chlorpromazine appears to exert a greater vasodilator 
effect on the venous system than on the arterial system. Therefore, the hemodynamic effect of this drug appears not to be similar to the effect of phenoxybenzamine, an alpha-blocking agent, but may have similarity to the effect of nitroglycerin which shows predominant dilation in the venous system. ${ }^{41}$

The action of chlorpromazine on the left ventricular performance remains unclear. Kido et al demonstrated an inhibitory action of chlorpromazine on the rabbits heart. ${ }^{13)}$ In contrast, Gulotta suggested that chlorpromazine increased left ventricular contractility in dogs. ${ }^{81}$ In clinical study, there have been few reports of the direct action on myocardium. But small doses of chlorpromazine may increase cardiac output slightly in patients with

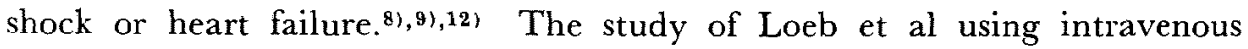
chlorpromazine in an average dose of $11 \mathrm{mg}$ demonstrated an increase in cardiac output in patients with shock. ${ }^{91}$ Similar result was observed in our present study. Cardiac index was slightly increased from an average of 2.11 to $2.28 \mathrm{~L} / \mathrm{min} / \mathrm{M}^{2}$.

There have been few published data on the time course of changes in cardiovascular effects after a single intramuscular injection of chlorpromazine in heart failure. As to sedative effect after a single injection, it has been demonstrated that the effect appears within 30 min and persists 2 to 4 hours. ${ }^{6}$ In the present study, however, left ventricular filling pressure was reduced significantly within $5 \mathrm{~min}$ and a peak reduction was observed at $15 \mathrm{~min}$. The significant effect persisted for 6 hours. Symptoms of pulmonary venous congestion such as stridor, dyspnea, or moist rales disappeared also within $15 \mathrm{~min}$ and the improvement persisted more than 6 hours. When the hemodynamic effects of chlorpromazine are compared with those of sublingually administered nitroglycerin or isosorbide dinitrate, the former exerts more rapid and longer effect than the latter. ${ }^{3), 4), 14)}$

Another beneficial effect of chlorpromazine is a sedative effect. In the presence of severe dyspnea due to actue pulmonary edema, patients react to it with pronounced anxiety and distress which increase the work of heart and oxygen demand. ${ }^{5)}$ Anxiety also increases respiratory rate with resultant augmentation of the work of the respiratory muscles. They may be reduced by the sedative effect of chlorpromazine. It has been assumed that chlorpromazine depresses the respiratory center by its effect on the brain stem. ${ }^{61}$ This effect may decrease hyperventilation and dyspnea. But, following a single intramuscular injection of small dose of chlorpromazine, the decrease in respiratory minute or tidal volumes has been reported to be minimal, ${ }^{151}$ and no significant changes of arterial $\mathrm{PO}_{2}$ and $\mathrm{PCO}_{2}$ were found in 4 patients in this study. 
In vasodilation therapy, a fall in blood pressure is of advantage to reduce afterload, but it may be of disadvantage to reduce perfusion pressure in the organs. Especially, in patients with acute myocardial infarction, whose cornary blood flow may be mainly dependent on the perfusion pressure because of severe coronary narrowing, perfusion pressure of the coronary artery is considered to be of great importance. The risk of hypotension after administration of chlorpromazine ${ }^{7)}$ has been pointed out. However, in the present study, the fall of blood pressure was slight and there was no patient who showed symptomatic hypotension or clinical deterioration even in those with acute myocardial infarction. For long term vasodilation therapy, shortacting agents such as phentolamine or sodium nitroprusside should be administered by drip infusion under careful and frequent monitoring of blood pressure because of the risk of profound hypotension. In contrast, the sustained action of chlorpromazine can eliminate the need for drip infusion and requiring less frequent administration. Further studies would be required to evaluate the effect of long term therapy by this agent, including oral administration of the agents in patients with chronic congestive heart failure.

\section{REFERENCES}

1. Majid PA, Sharma B, Taylor SH: Phentolamine for vasodilator treatment of severe heart failure. Lancet 2: 719, 1971

2. Guiha NH, Cohn JN, Mikulic E, Franciosa J, Limus CJ: Treatment of refractory heart failure with infusion of nitroprusside. N Engl J Med 291: 587, 1974

3. Franciosa JA, Mikulic E, Cohn JN, Jose E, Fabie A: Hemodynamic effects of orally administered isosorbide dinitrate in patients with congestive heart failure. Circulation 50: 1020,1974

4. Mifune J, Kuramoto K, Ueda K, Matsushita S, Kuwajima I, Sakai M, Ikehata K, Kitano K, Murakami M: Vasodilation therapy in congestive heart failure--hemodynamic effects of isosorbide dinitrate and nitroglycerin. Shinzo 8: 1427, 1976 (in Japanese)

5. Goldberg LI: Pharmacology of cardiovascular drugs. in The Heart, ed by Hurst JW, 3rd ed, McGraw-Hill, NY, P 1559, 1970

6. Byck R: Drugs and the treatment of psychiatric disorfiers. in The Pharmacological Basis of Therapeutics, ed by Goodmann LS, Gilman A, 5th ed, Macmillian, NY, P 152, 1975

7. Stimmel B: The effects of mood altering durgs on the heart, in Drugs in Cardiology, Vol 1, Part 1, ed by Donose E, 1st ed, Grune \& Stratton, NY, p 203, 1975

8. Gulotta SJ: Chlorpromazine in the treatment of cardiogenic shock. Am Heart J 80: 570, 1970

9. Loeb HS, Pietras RJ, Ninos N, Tobin J, Gunnar RM: Hemodynamic responses to chlorpromazine in patients in shock. Arch Intern Med 124: 354, 1969

10. Ganz W, Swan HJC: Measurement of blood flow by thermodilution. Am J Cardiol 29: 241,1972

11. Mason DT; Regulation of cardiac performance in clinical heart disease. in Congestive Heart Failure, ed by Mason DT, 1st ed, Grune \& Stratton, NY, P 111, 1976

12. Elkayam U, Rotmensch HH: Hemodynamic effects of chlorpromazine in patients with acute myocardial infarction and pump failure. Chest 72:623, 1977 
13. Kido R, Hirose K, Yamamoto K, Hiraoka K: Pharmacology of chlorpromazine. Ann Rept Shionogi Res Lab 6: 171, 1956 (in Japanese)

14. Mifune J, Kuramoto K, Ueda K, Matsushita S, Kuwajima I, Sakai M, Iwasaki T, Inoue $\mathbf{H}$, Shinagawa T, Murakami M: Hemodynamic comparisons between oral and sublingual isosorbide dinitrate in heart failure (abstr). Jap Circulat J 41: 786, 1977

15. Dobkin AB, Gilbert RGB, Lamoureu L: Physiological effects of chlorpromazine. Anaesthesia $9: 157,1954$ 